\title{
Hypoxic Preconditioning Increases the Neuroprotective Effects of Mesenchymal Stem Cells in a Rat Model of Spinal Cord Injury
}

Takeshi Imura1, Mayumi Tomiyasu1', Naofumi Otsuru', Kei Nakagawa1, Takashi Otsuka1, Shinya Takahashi², Masaaki Takeda ${ }^{3}$, Looniva Shrestha1, Yumi Kawahara ${ }^{4}$, Takahiro Fukazawa ${ }^{5}$, Taijiro Sueda², Keiji Tanimoto ${ }^{6}$ and Louis Yuge ${ }^{1,4^{*}}$

${ }^{1}$ Bio-Environmental Adaptation Sciences, Graduate School of Biomedical \& Health Sciences, Hiroshima University, Japan

${ }^{2}$ Department of Cardiovascular Surgery, Hiroshima University Hospital, Japan

${ }^{3}$ Department of Neurosurgery, Graduate School of Biomedical \& Health Sciences, Hiroshima University

${ }^{4}$ Space Bio-Laboratories Co., Ltd., Japan

${ }^{5}$ Natural Science Center for Basic Research and Development, Hiroshima University, Japan

${ }^{6}$ Department of Radiation Medicine, Research Institute for Radiation Biology and Medicine, Hiroshima University, Japan

\begin{abstract}
The functional deficit caused by Spinal Cord Injury $(\mathrm{SCl})$ is clinically incurable and current treatments have limited effects. Previous studies have suggested that cell-based therapy using Mesenchymal Stem Cells (MSCs) pre-treated with drugs or gene transfection have possible therapeutic effects. Hypoxic preconditioning is one of the most likely treatments of cell-based therapy without altering genes; however, few reports are available about Hypoxia-Preconditioned MSCs (H-MSC) transplantation for SCl. Here we demonstrate the therapeutic potential of $\mathrm{H}-\mathrm{MSC}$ transplantation using $\mathrm{SCl}$ model rats. $\mathrm{H}-\mathrm{MSC}$ expressed significantly higher mRNA levels of vascular endothelial growth factor-1 and carbonic anhydrase IX, hypoxia inducible genes. H-MSC transplantation resulted in remarkable functional improvement in the $\mathrm{SCl}$ model rats compared to no transplantation. Expression of brainderived neurotrophic factor and the autophagy-associated marker beclin1 mRNA was significantly upregulated in rat spinal cord that underwent $\mathrm{H}-\mathrm{MSC}$ transplantation. Furthermore, conditioned medium of the H-MSC significantly prevented cell death of NG108-15 cells exposed to oxidative or inflammatory stress. These results suggest that hypoxia preconditioning is an effective strategy for $\mathrm{SCl}$ in cell-based therapy using MSCs.
\end{abstract}

Keywords: Cell-based therapy; Spinal cord injury; Mesenchymal stem cells; Hypoxic culture; Preconditioning; Neuroprotection; Vegf

\section{Introduction}

Although current therapies, such as novel drugs [1] or neurorehabilitation [2] have been developed to treat Spinal Cord Injury (SCI), these therapies could not achieve radical cure. Cell-based therapy using Mesenchymal Stem Cells (MSCs) has been gaining attention as a novel approach to treat the damage caused by SCI. MSCs can be isolated from various tissues, such as bone marrow [3] or adipose tissue [4], and have self-renewal and multi-lineage differentiation potential. Animal experiments [5] and clinical trials [6,7] have revealed that MSCs transplantation reduces lesion volume and promotes functional improvement of central nervous system disorders including SCI.

The mechanisms of functional recovery after MSCs transplantation to treat SCI were suggested as 1) homing and neural differentiation of transplanted MSCs in the lesion site [8], 2) modulation of the inflammatory reaction by transplanted MSCs [9], 3) paracrine effects mediated by chemokines and growth factors released from transplanted MSCs, such as Neurotrophins (NT) 1 or 2, Brain-Derived Neurotrophic Factor (BDNF), Grail cell line-Derived Neurotrophic Factor (GDNF), and Vascular Endothelial Growth Factor (VEGF) [10-12]. However, the differentiation potential of MSCs in vivo remains unclear because very few transplanted MSCs are detected at the lesion site [11]. Thus, it has been proposed and commonly accepted that the functional benefits of MSCs transplantation are due to a paracrine effect $[11,13]$. The pathology of traumatic SCI results from primary damage (initial mechanical damage) and secondary damage due to vascular and biochemical effects [14]. MSCs transplantation to treat traumatic SCI is expected to reduce secondary damage of the spinal cord through a paracrine neuroprotective effect.

Transplanting pre-treated MSCs using drugs [15] or gene transfection [16] has highly therapeutic effects in disease models.
Culturing cells under hypoxic conditions is a less invasive, alternative method to pre-condition of transplanted cells [17-19]. Although MSCs are usually cultured under normoxic conditions, MSCs exist in low oxygen (hypoxic) conditions in vivo [20] and the oxygen tensions are an important factor during MSC culture because stem cells are particularly sensitive to their microenvironment [21]. VEGF is known as a key regulator of vasculogenesis and angiogenesis [22]. In addition, VEGF has neurotrophic and neuroprotective effects in vitro and in vivo $[23,24]$. Although several studies have demonstrated that VEGF mRNA or protein expression is upregulated in hypoxia-preconditioned MSCs [25-27], few reports have demonstrated the neuroprotective effects of hypoxia-preconditioned MSCs transplantation to treat SCI. Therefore, the present study aimed to determine whether hypoxia-preconditioned MSCs have a neuroprotective effect in vitro and in vivo and improve functional defects in a rat model of SCI.

\section{Materials and Methods}

All protocols in this study were approved by the Animal Testing Committee Guidelines at Hiroshima University. Animal care and

*Corresponding author: Louis Yuge, Division of Bio-Environmental Adaptation Sciences, Graduate School of Biomedical and Health Sciences, Hiroshima University, 1-2-3 Kasumi, Minami-ku, Hiroshima 734-8551, Japan, Tel: 81-82257-5425; Fax: 81-82-257-5344; E-mail: ryuge@hiroshima-u.ac.jp

Received January 04, 2017; Accepted January 30, 2017; Published January 31, 2017

Citation: Imura T, Tomiyasu M, Otsuru N, Nakagawa K, Otsuka T, et al. (2017) Hypoxic Preconditioning Increases the Neuroprotective Effects of Mesenchymal Stem Cells in a Rat Model of Spinal Cord Injury. J Stem Cell Res Ther 7: 375. doi: 10.4172/2157-7633.1000375

Copyright: ( 2017 Imura T, et al. This is an open-access article distributed under the terms of the Creative Commons Attribution License, which permits unrestricted use, distribution, and reproduction in any medium, provided the original author and source are credited. 
handling procedures were in accordance with National Institutes of Health guidelines.

\section{Isolation and differentiation of rMSCs}

Rat MSCs (rMSCs) were harvested from the femurs and tibias of 3-week-old Sprague-Dawley (SD) rats. The cells were seeded onto a culture dish (Sumitomo Bakelite Co., Tokyo, Japan) and cultured in Dulbecco's Modified Eagle Medium with low glucose (DMEM-L) (Sigma-Aldrich Co., St Louis, MO, USA) supplemented with $10 \%$ fetal bovine serum (Thermo Fisher Scientific, Waltham, MA, USA), penicillin (100 units $/ \mathrm{ml})$, and streptomycin $(100 \mu \mathrm{g} / \mathrm{ml}$ : both from Sigma-Aldrich). The cells were maintained at $37^{\circ} \mathrm{C}$ in $5 \% \mathrm{CO}_{2}$, and the medium was changed every 3 days.

The cell differentiation assay was performed using the Rat Mesenchymal Stem Cell Functional Identification Kit (R \& D Systems, Inc., Minneapolis, MN, USA), according to the manufacturer's protocol. The cells were finally stained with Oil Red-O solution (Wako Pure Chemical Industries, Osaka, Japan) for $15 \mathrm{~min}$ or with Alizarin Red-S solution (Sigma-Aldrich) for $30 \mathrm{~min}$.

\section{Cell culture under hypoxic conditions}

rMSCs were seeded $\left(2 \times 10^{4}\right.$ cells $\left./ \mathrm{cm}^{2}\right)$ onto a culture dish for 24 $\mathrm{h}$. Then, the cells were cultured under normoxic $(21 \%$ partial pressure of oxygen $\left.\left[\mathrm{pO}_{2}\right]\right)$ or hypoxic $\left(10 \%, 5 \%, 2 \%\right.$, or $\left.1 \% \mathrm{pO}_{2}\right)$ conditions in a hypoxic chamber. After a $24 \mathrm{~h}$ culture, the cells were collected in phosphate-buffered saline (PBS).

\section{Reverse transcription and real-time polymerase chain reaction $(\mathrm{PCR})$}

Total RNA was extracted with NucleoSpin ${ }^{\circ}$ RNA (MACHEREYNAGEL GmbH \& Co. KG, Düren, Germany) according to the manufacturer's protocol. cDNA was synthesized with ReverTra Ace- $\alpha$ (Toyobo Co., Ltd., Osaka, Japan). Real-time PCR was performed using a 7500 Real-Time PCR system (Applied Biosystems, Carlsbad, CA, USA) and the Fast Start Universal Probe Master (Roche, Basel, Switzerland) according to the manufacture's protocol. Real-time PCR was performed using oligonucleotide primer sets corresponding to the cDNA sequences of rat carbonic anhydrase IX (Car9), adrenomedullin (Adm), Bdnf, Gdnf, Vegf, b-cell leukemia/lymphoma 2 protein (Bcl2), and $\mathrm{Bcl} 2$-associated $\mathrm{X}$ protein (Bax). Beta actin (Actb) was used as an endogenous control.

\section{Surgical procedure and cell transplantation}

Adult male SD rats (weight, 150-250 g) were used for constructing a spinal-contusion model using a weight-dropping method [28]. The rats were anesthetized, and a midline linear incision was made over the thoracic (Th) 9-11 spinous processes. The laminae of Th9-11 were exposed by dissecting the bilateral paraspinal muscle laterally. A laminectomy was carried out at Th10. A brass cylinder $(10 \mathrm{~g})$ was dropped onto an impactor rod that rested on the surface of the spinal cord at Th10. A spinal contusion was made with a force of $50 \mathrm{~g} / \mathrm{cm}$. Following the injury, the skin was sutured to close the lesion. SCI rats received passive joint motion exercises daily to prevent hind limb joint contracture after the surgical procedure. Prophylactic antibiotics were administered for 5 days postoperatively, and their bladders were expressed manually twice daily until sufficient recovery of autonomic bladder function. The rats were divided into the following three groups according to the treatment received: transplantation of MSCs cultured under normoxic conditions (N-MSC); transplantation of MSCs cultured under hypoxic ( $\left.1 \% \mathrm{pO}_{2}\right)$ conditions for $24 \mathrm{~h}$ (H-MSC); and only PBS administration (Ctrl). Rats in the N-MSC and H-MSC groups were injected the conditioned MSCs $\left(5 \times 10^{5}\right.$ cells/300 $\mu \mathrm{l}$ PBS) intravenously $24 \mathrm{~h}$ after surgery.

\section{Motor functional analysis}

The inclined plane test and the Basso-Beattie-Bresnahan locomotor rating scale (BBB scale) were used to evaluate hind limb function. As reported previously, the inclined plane test assesses the maximum angle at which the animal can maintain its position for $5 \mathrm{~s}$ on an inclined plane [29]. The BBB scale is a 22-point scale that systematically and logically follows recovery of hind limb function, and ranges from a score of 0 , indicative of no observed hind limb movement, to a score of 21 , representative of a normal ambulating rodent [30]. Motor functional analyses were performed before SCI and on days $0-7,10,14$, and 21 after SCI.

\section{Spinal cord tissue sampling and mRNA expression analysis of the spinal cord lesion site}

The rats were anesthetized $24 \mathrm{~h}$ after MSC transplantation. Spinal cord tissues were removed and soaked in RNA Later (Sigma-Aldrich). Total RNA was extracted from injured spinal cord segments $(2 \mathrm{~mm}$ centered on the lesion site). RNA extraction and reverse transcription were performed as described above. Real-time PCR was performed using oligonucleotide primer sets corresponding to the cDNA sequences of rat Bdnf, Gdnf, Bcl2, Bax, beclin 1 (Becn1), interleukin-1 beta (Il1b), interleukin-10 (Il10), tumor necrosis factor alpha (Tnfa), and tumor necrosis factor receptor superfamily, member 1A (Tnfrsf1a). Actb was used as an endogenous control.

\section{Preparation of rMSC conditioned medium and NG108-15 cell culture}

rMSCs were seeded onto a culture dish and maintained in growth medium. After reaching $80 \%$ confluent, medium was changed to fresh growth medium and cells were cultured in normoxic $\left(21 \% \mathrm{pO}_{2}\right)$ or hypoxic $\left(1 \% \mathrm{pO}_{2}\right)$ condition. $24 \mathrm{~h}$ after exposed to normoxic or hypoxic conditions, the culture medium were collected from both culture conditions as Conditioned Medium (CM). After $0.2 \mu \mathrm{m}$ filtration, $\mathrm{N}-\mathrm{MSC}-\mathrm{CM}$ and $\mathrm{H}-\mathrm{MSC}-\mathrm{CM}$ were stored at $-80^{\circ} \mathrm{C}$.

NG108-15 (ECACC, Porton Down, UK) neural cells were cultured in Dulbecco's. Modified Eagle's medium with high glucose (DMEM-H) (Sigma-Aldrich Co.) supplemented with 10\% FBS (Thermo Fisher Scientific), penicillin (100 units $/ \mathrm{ml})$, streptomycin $(100 \mu \mathrm{g} / \mathrm{ml}$ : both from Sigma-Aldrich), and HAT supplement (Thermo Fisher Scientific). The cells were maintained at $37^{\circ} \mathrm{C}$ in $5 \% \mathrm{CO}_{2}$.

\section{Oxidative or inflammatory stress exposure to NG108-15 and cell death assay}

NG108-15 cells were exposed to oxidative or inflammatory stress to evaluate the neuroprotective effect of N-MSC-CM or H-MSC-CM. Growth medium of rMSCs (absence of rMSCs culture) was used as a control. $\mathrm{H}_{2} \mathrm{O}_{2}$ (Santoku Chemical Industries, Tokyo, Japan) was used to mimic an oxidative stimulus to cells [31]. Lipopolysaccharide (LPS) (Wako pure chemical industries, Osaka, Japan) was used to mimic an inflammatory stimulus to cells [9]. As preliminary experiment, NG10815 cells were cultured in different concentrations of $\mathrm{H}_{2} \mathrm{O}_{2}$ or LPS to determine optimal condition, and $500 \mu \mathrm{M} \mathrm{H}_{2} \mathrm{O}_{2}$ and $200 \mathrm{ng} / \mathrm{ml} \mathrm{LPS}$ were determined as optimal condition for stress exposed experiment (Supplementary Figure S1A and S1B). NG108-15 cells were seeded onto culture dish (Sumitomo Bakelite Co.) and maintained in growth 
medium. The medium was changed to fresh rMSCs growth medium (Ctrl), N-MSC-CM, or H-MSC-CM (with $500 \mu \mathrm{M} \mathrm{H_{2 }} \mathrm{O}_{2}$ or $200 \mathrm{ng} /$ $\mathrm{ml}$ LPS) $48 \mathrm{~h}$ after seeding. The cells were collected and centrifuged $24 \mathrm{~h}$ after exposure to stress. The cells were centrifuged, suspended in PBS, and cell survival rate was determined with a counting chamber (Sunlead Glass Corp., Saitama, Japan) using trypan blue stain, and the remaining cells were collected for the mRNA expression analysis.

\section{mRNA expression analysis of stress exposed NG108-15 cells}

Total RNA was extracted from the NG108-15 cells samples and reverse transcription was performed as described above. Real-time PCR was performed using oligonucleotide primer sets corresponding to the cDNA sequences of rat Bcl2, Bax, Becn1, and Tnfrsf1a. Actb was used as an endogenous control.

\section{Statistical analysis}

Data were evaluated using one-way analysis of variance (ANOVA) with the Bonferroni test for mRNA expression analysis. Two-way ANOVA with the Bonferroni test was used for the motor functional analysis. Statistical analyses were performed using the JSTAT software (Sato, Japan). A p-value $<0.05$ was considered significant.

\section{Results}

\section{Differentiation potential of rMSCs}

The differentiation potential of the isolated rMSCs into adipocytes and osteoblasts was estimated to identify as the MSCs. Before differentiation, rMSCs were negative for specific staining (Oil Red-O and Arizarin Red-S staining), but positive cells were observed after differentiation (data not shown).

Effects of hypoxic culture conditions on growth factor or apoptotic-associated mRNA expression

rMSCs were cultured under five different conditions to determine the optimal oxygen level. Expression of the known hypoxia inducible genes, Car9 and Vegf increased significantly only under the $1 \% \mathrm{pO}_{2}$ condition compared with that under the normoxic condition (Figure $1 \mathrm{~A}$ and $1 \mathrm{~B}$ ). Adm also showed tendency to increase under the $1 \% \mathrm{pO} 2$ condition, although this was not significant (Figure 1C). No differences in expression levels of Bdnf, Gdnf, and the Bax/Bcl2 ratio, an apoptotic indicator, were observed among those conditions (Figure 1D-1F).

\section{Behavioral recovery of spinal cord injured rats}

We assessed motor function using the inclined plane test and the $\mathrm{BBB}$ scale to compare the functional benefits of N-MSC and H-MSC transplantation after SCI. As a result, rats in the H-MSC group demonstrated more significant improvements on the inclined plane test than those in the Ctrl group at 14 and 28 days after injury (Figure 2A). The BBB scale also showed that the H-MSC group rats seemed to improve more compared with those in the other groups, although the differences were not significant (Figure 2B). Rats in the N-MSC group seemed to improve motor functions, but the differences were not significant.

\section{Effects of hypoxia-preconditioned MSCs transplantation on mRNA expression of the spinal cord lesion site}

In order to clarify the role of transplanted H-MSC in spinal cord lesion site, mRNA levels of neurotrophic factor, inflammatory, or apoptotic genes were evaluated. The Bdnf mRNA expression level was significantly higher in the spinal cords of rats in the H-MSC group than those in the Ctrl group (Figure 3A). Gdnf mRNA expression tended to be higher in the H-MSC group, but not significant (Figure 3B). The autophagy-associated marker, Becn1 was also significantly higher in
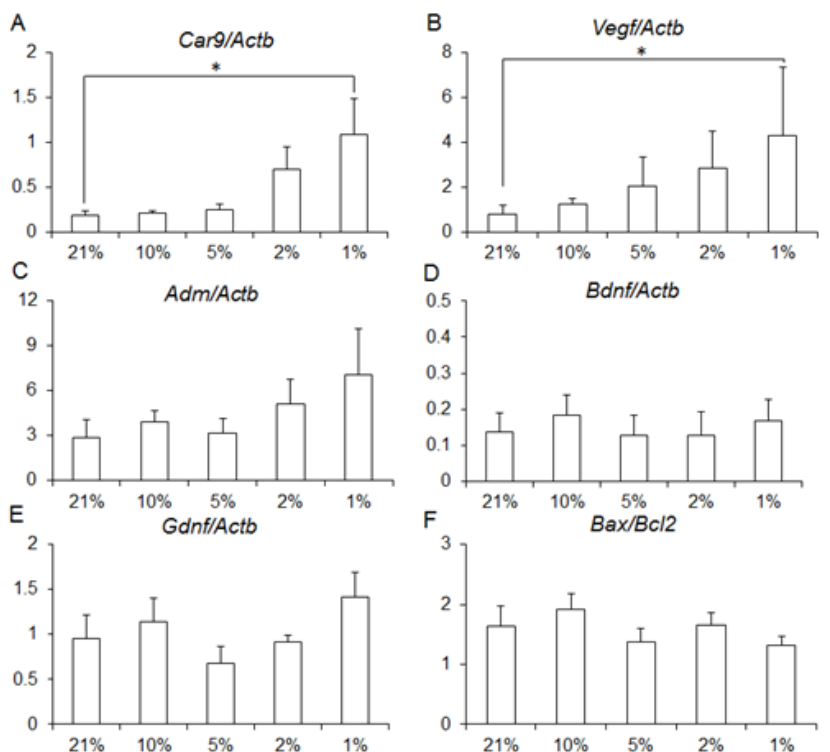

Figure 1: Oxygen level-dependent mRNA expression of MSCs, mRNA expression levels of Car9 (A), Vegf (B), Adm (C), Bdnf (D), Gdnf (E), and Bax/ Bcl2 $(F)$. Data are mean \pm SE of independent experiments $(p<0.05, n=4)$.

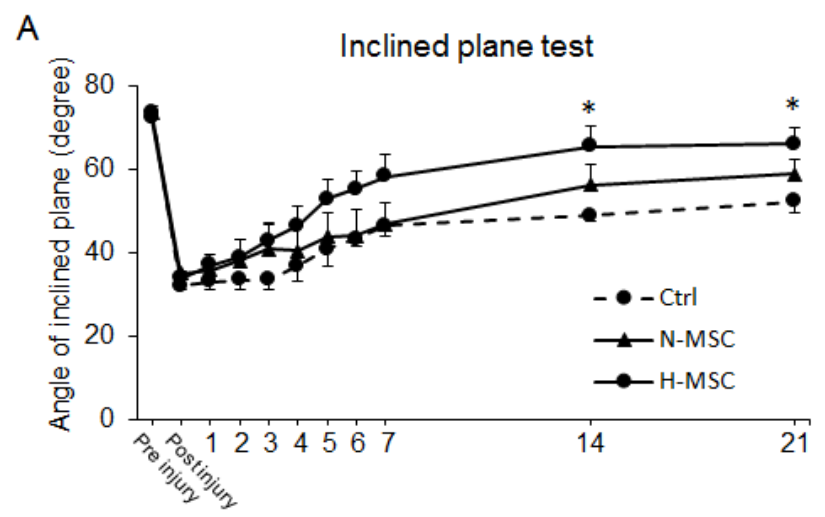

B

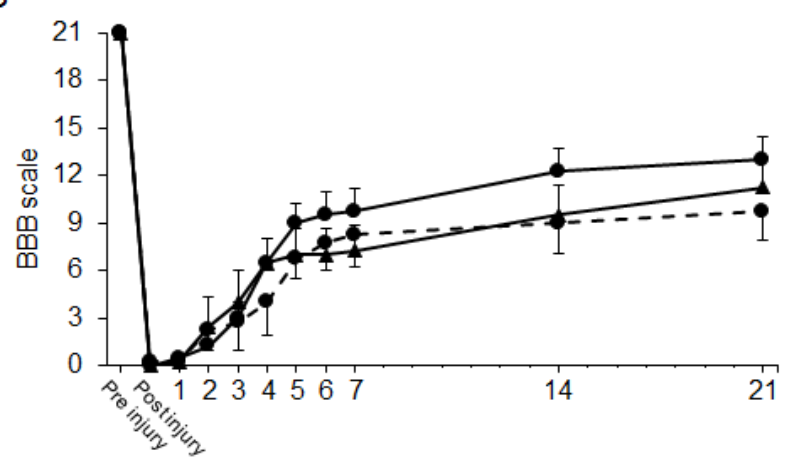

Figure 2: Effect of H-MSC transplantation on motor functional improvement, Results of the inclined plane test (A) and the BBB score (B). Data are mean \pm SE. *Group H-MSC vs. group Ctrl $(p<0.05, n=4)$. 
rats in the H-MSC group than those in the Ctrl and N-MSC groups (Figure $3 \mathrm{C}$ ). On the other hand, no differences in the $\mathrm{Bax} / \mathrm{Bcl} 2$ ratio or the inflammatory-associated markers, Illb, Il10, Tnfa, and Tnfrsfla were observed (Figure 3D-3H).

\section{Survival rate and mRNA expression of stress-exposed NG108- 15 cells}

In order to estimate paracrine effects of H-MSC, effects of conditioned medium of MSC on stress induced cell death of neural cell were evaluated. As a result, the survival rate of NG108-15 cells exposed to oxidative or inflammatory stress was significantly higher in cells in the H-MSC-CM than those in the N-MSC-CM or Ctrl (Figure 4).

mRNA expression in NG108-15 cells exposed to oxidative or inflammatory stress was analyzed. The $\mathrm{Bax} / \mathrm{Bcl} 2$ ratio in the oxidative stress exposed NG108-15 cells was significantly lower in cells cultured in H-MSC-CM than those in N-MSC-CM or the Ctrl, (Figure 5Aa), but no differences was observed among the three groups in inflammatory stress exposure experiment (Figure 5Ba). On the other hand, Becn1 expression was significantly higher in $\mathrm{H}-\mathrm{MSC}-\mathrm{CM}$ than that in the Ctrl in both experiments (Figure $5 \mathrm{Ab}$ and $5 \mathrm{Bb}$ ). Furthermore, Tnfrsfla expression level in the inflammatory stress exposed NG108-15 cells was significantly lower in cells cultured in H-MSC-CM than that in $\mathrm{N}-\mathrm{MSC}-\mathrm{CM}$ and the Ctrl, and its expression level was significantly lower also in cells cultured in N-MSC-CM, compared to those in the Ctrl (Figure 5Bc).
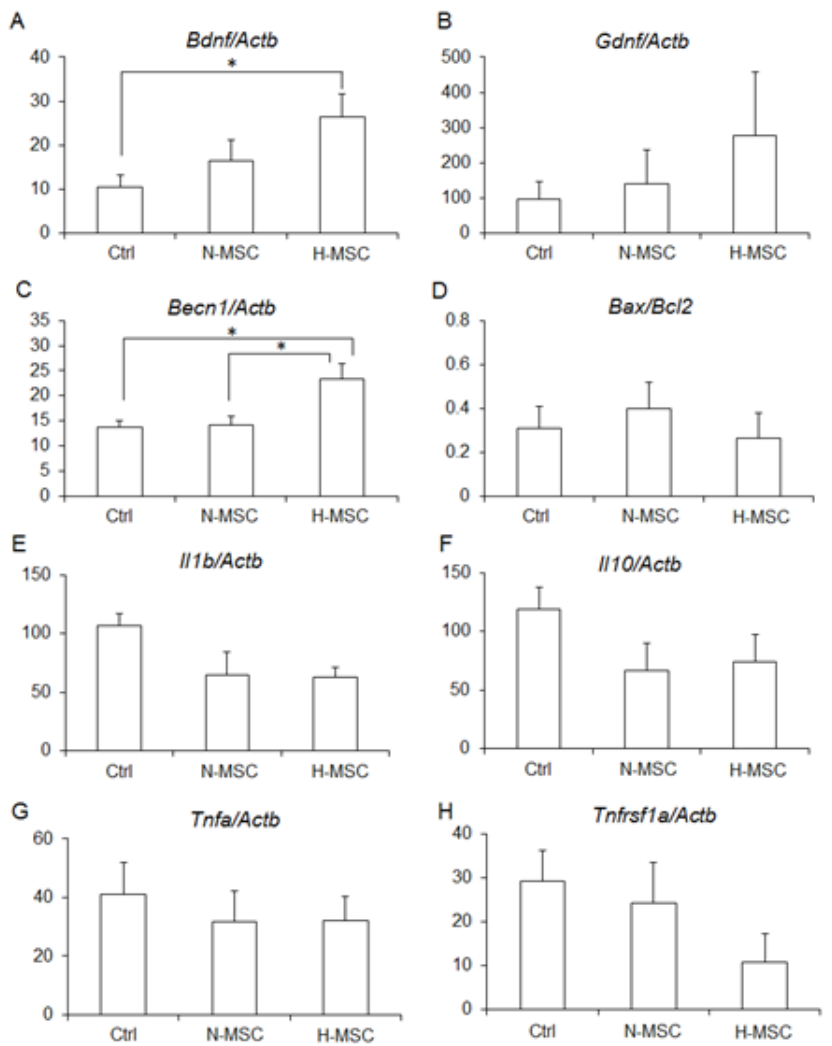

Figure 3: mRNA expression levels in the spinal cord lesion site, mRNA expression levels of Bdnf (A), Gdnf (B), Becn1 (C), Bax/Bcl2 (D), II1b (E), II10 $(F)$, Tnfa $(G)$, and Tnfrsf1a $(H)$. Data are mean \pm SE of independent experiments $(p<0.05, n=4)$.
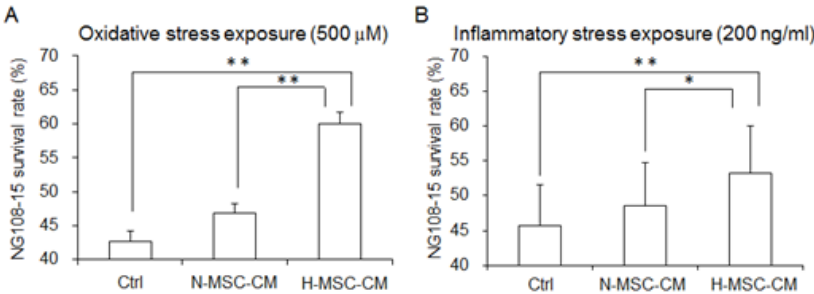

Figure 4: Effect of conditioned medium on survival rate of stress exposed NG108-15 cells, Survival rate of NG108-15 cells exposed to oxidative stress (A) and inflammatory stress (B). Data are mean \pm SE of independents experiments $\left({ }^{*} p<0.05,{ }^{* *} p<0.01, n=8\right)$.

A Oxidative stress exposure
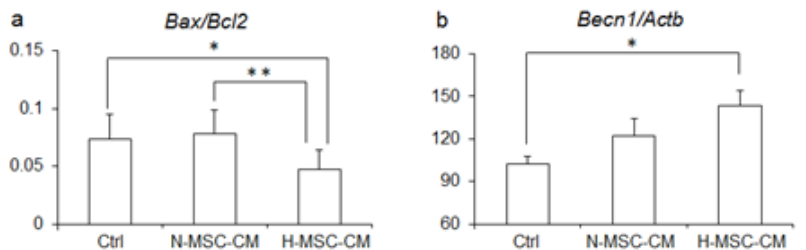

B
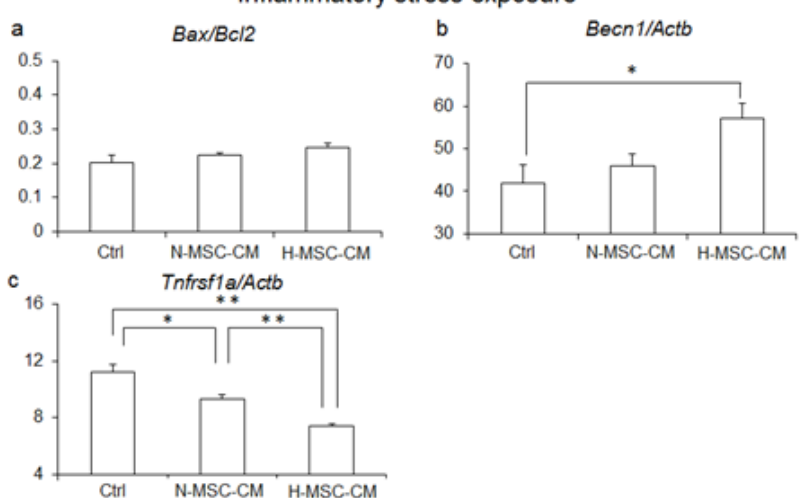

Figure 5: mRNA expression levels of stress exposed MSCs (A) mRNA expression of Bax/Bcl2 (a) and Becn1 (b) in MSCs exposed to oxidative stress. (B) mRNA expression of Bax/Bcl2 (a), Becn1 (b), and Tnfrsf1a (c) in MSCs exposed to inflammatory stress. Data are mean \pm SE of independent experiments $\left({ }^{*} p<0.05,{ }^{* *} p<0.01, n=8\right)$.

\section{Discussion}

In the present study, we investigated whether hypoxiapreconditioned MSCs had a neuroprotective effect in vitro and in vivo, and demonstrated that hypoxia preconditioning was an effective strategy for SCI in cell-based therapy using MSCs.

Although previous studies have reported the hypoxic culture conditions for preconditioning of cell-based therapy [17-19], the optimal culture conditions remain unknown. In this study, Car9 and Vegf expression increased significantly in rMSCs under the $1 \% \mathrm{pO}_{2}$ hypoxic condition compared with that under the normoxic condition. Car9 is a hypoxia-induced protein involved in $\mathrm{pH}$ regulation and a target gene of hypoxia-inducible factor-1 (HIF-1), which is one of the master regulator in hypoxic response [32]. Vegf is also a well-known hypoxia-inducible gene, and important for signalling migration of endothelial cells and induction of angiogenesis [25]. Our results suggest 
Citation: Imura T, Tomiyasu M, Otsuru N, Nakagawa K, Otsuka T, et al. (2017) Hypoxic Preconditioning Increases the Neuroprotective Effects of Mesenchymal Stem Cells in a Rat Model of Spinal Cord Injury. J Stem Cell Res Ther 7: 375. doi: 10.4172/2157-7633.1000375

Page 5 of 7

that hypoxic preconditioning in this study effectively activated adaptive signaling in rMSCs against hypoxia-relating stress stimuli. On the other hand, no differences in the $\mathrm{Bax} / \mathrm{Bcl} 2$ ratio were detected among the five different pO2 conditions for $24 \mathrm{~h}$. Potier et al. reported that exposure to hypoxia over $72 \mathrm{~h}$ can lead to massive MSC death [33], but no remarkable cell mortality was observed under our study conditions, suggesting that $1 \% \mathrm{pO}_{2}$ for $24 \mathrm{~h}$ was enough condition for expressing neurotrophic/angiogenesis genes.

Rats in the H-MSC group showed significant functional recovery compared to those in the Ctrl group. Bdnf and Becn 1 mRNA expression levels at the spinal cord lesion site of rats in the H-MSC group were significantly higher than those in the Ctrl group. BDNF plays an important role in survival and differentiation of various neural cells types during neural development and after brain injury, which affect functional recovery [34-36]. Although BDNF was reported to play a role in regulating VEGF expression [37,38], it has been recently confirmed that BDNF expression and action are dependent on the vascular endothelial growth factor receptor-2 identifying BDNF as a downstream signaling partner of VEGF $[39,40]$. Moreover, VEGF together with BDNF accelerate brain plasticity after stroke [41]. In this study, H-MSC expressed a high level of Vegf, which may affect Bdnf expression at the spinal cord lesion site. Becn1 is autophagy-related gene and has been described as an essential autophagy effector [42]. Chen et al. reported that autophagy is essential for maintaining cellular homeostasis during the stress response, and they concluded that BDNF may be a novel neuroprotective candidate for upregulating autophagy [43]. In addition, it has been suggested that VEGF attenuates SCI by increasing autophagy [44]. Taken together, our results suggest that Vegf expression of transplanted H-MSCs and/or Bdnf expression at the spinal cord lesion site promote autophagy for neuroprotective remodeling, resulting motor functional recovery. Although hypoxic preconditioning is able to improve the therapeutic potential of $\mathrm{H}-\mathrm{MSC}$, previous researches reported the epigenetic changes due to hypoxia culture [45-48]. Therefore, it is still essential to investigate the epigenetic changes in the MSCs cultured in the hypoxia condition.

The neuroprotective paracrine effect of hypoxia-preconditioned MSCs were analyzed in vitro using NG108-15 cells in this study. Various secondary injuries such as oxidative stress and inflammation contribute to cell death and functional disability after SCI $[49,50] . \mathrm{H}_{2} \mathrm{O}_{2}$ and LPS are used to mimic this environment in vitro [9,31]. In the present study, the survival rate of NG108-15 cells exposed to oxidative stress or inflammatory stress was significantly higher in cells maintained in the H-MSC-CM than in the N-MSC-CM or Ctrl. The Bax/Bcl2 ratio was significantly lower and Becnl expression was significantly higher in H-MSC-CM when NG108-15 cells were exposed oxidative stress. Reactive oxygen species-induced activation of apoptosis signalregulating kinase 1 (ASK1) plays crucial roles in oxidative stressmediated cell death [51]. Nako et al. reported that VEGF treatment prevents oxidative stress-induced endothelial apoptosis by inhibiting activation of ASK [52]. In addition, VEGF upregulates the expression of Becn1, which is an autophagy-related gene [44]. In this study, we assumed that H-MSC-CM included VEGF secreted from cultured H-MSCs, which inhibited ASK activation and upregulated Becn1 expression, resulting inhibition of the cell death of NG108-15 cells exposed to oxidative stress. Regarding the inflammatory stress exposure, Tnfrsfla expression was significantly lower and Becn1 expression was significantly higher in cells maintained in H-MSC-CM than those in $\mathrm{N}$-MSC-CM or the Ctrl. LPS is a well-known trigger of tumor necrosis factor (Tnf) expression in inflammation and neural cell death. TNF is a proinflammatory cytokine that exerts its action through the TNF receptor superfamily [53]. Previous studies have shown that both TNF and the TNF receptor are upregulated after nerve injury [54,55]. Moreover, Wang et al. reported that MSCs inhibit LPS-stimulated signaling in hepatic stellate cells [56]. In this study, H-MSC-CM may suppress inflammatory signal and upregulate Becn1 expression, which prevented death of NG108-15 cells exposed to inflammatory stress.

Although previous studies reported that MSCs transplantation reduces lesion volume and promotes functional improvement of central nervous system disorders including SCI [5-7], we did not observe significant motor functional improvement with N-MSC transplantation in this study. We have also reported therapeutic effect of neural stem cell transplantation in brain injury model [34]. In this study, we could find effective improvement of motor functions with half number of H-MSC transplantation compared to our previous study using mice model, but did not that with N-MSC. Optimization of MSCs transplantation must be necessary in next step to reach future clinical trial.

\section{Conclusion}

We here provide novel evidence that hypoxia-preconditioned MSCs accelerated functional recovery in SCI model rats, at least through secretion of protective cytokines and induction of autophagy for tissue remodeling. Although optimization of transplantation protocol is needed, our results suggest that hypoxia preconditioning of MSCs is a useful strategy for cell-based therapy.

\section{Acknowledgement}

This study was supported, in part, by the Japan Society for the Promotion of Sciences (JSPS) KAKENHI Grant Number 15H06430.

\section{References}

1. Vasconcelos ND, Gomes ED, Oliveira EP, Silva CJ, Lima R, et al. (2016) Combining neuroprotective agents: effect of riluzole and magnesium in a rat model of thoracic spinal cord injury. Spine J 16: 1015-1024. [PubMed]

2. van den Brand R, Heutschi J, Barraud Q, DiGiovanna J, Bartholdi K, et al (2012) Restoring voluntary control of locomotion after paralyzing spinal cord injury. Science 336: 1182-1185.

3. Pittenger MF, Mackay AM, Beck SC, Jaiswal RK, Douglas R, et al. (1999) Multilineage potential of adult human mesenchymal stem cells. Science 284 : 143-147. [PubMed]

4. Zuk PA, Zhu M, Ashjian P, De Ugarte DA, Huang JI, et al. (2002) Human adipose tissue is source of multipotent stem cells. Mol Biol Cell 13: 4279-4295. [PubMed]

5. Chen J, Li Y, Katakowski M, Chen X, Wang L, et al. (2003) Intravenous bone marrow stromal cell therapy reduces apoptosis and promotes endogenous cell proliferation after stroke in female rat. J Neurosci Res 73: 778-786. [PubMed]

6. Honmou O, Houkin K, Matsunaga T, Niitsu Y, Ishiai S, et al. (2011) Intravenous administration of auto serum-expanded autologous mesenchymal stem cells in stroke. Brain 134: 1790-1807. [PubMed]

7. Lee JS, Hong JM, Moon GJ, Lee PH, Ahn YH, et al. (2010) A long-term followup study of intravenous autologous mesenchymal stem cell transplantation in patients with ischemic stroke. Stem Cells 28: 1099-1106. [PubMed]

8. Chen J, LiY, Chopp M (2000) Intracerebral transplantation of bone marrow with BDNF after MCAo in rat. Neuropharmacology 39: 711-716. [PubMed]

9. Neirinckx V, Agirman G, Coste C, Marquet A, Dion V, et al. (2015) Adult bone marrow mesenchymal and neural crest stem cells are chemoattractive and accelerate motor recovery in a mouse model of spinal cord injury. Stem Cell Res Ther 6: 211. [PubMed]

10. Caplan Al, Dennis JE (2006) Mesenchymal stem cells as trophic mediators. J Cell Biochem 98: 1076-1084. [PubMed]

11. Hess DC, Borlongan CV (2008) Stem cells and neurological disease. Cell Prolif 41: 94-114. [PubMed]

12. Parr AM, Tator $\mathrm{CH}$, Keating A (2007) Bone marrow-derived mesenchymal 
Citation: Imura T, Tomiyasu M, Otsuru N, Nakagawa K, Otsuka T, et al. (2017) Hypoxic Preconditioning Increases the Neuroprotective Effects of Mesenchymal Stem Cells in a Rat Model of Spinal Cord Injury. J Stem Cell Res Ther 7: 375. doi: 10.4172/2157-7633.1000375

stromal cells for the repair of central nervous system injury. Bone Marrow Transplant 40: 609-619. [PubMed]

13. Chopp M, Li Y (2002) Treatment of neural injury with marrow stromal cells. Lancet Neurol 1: 92-100. [PubMed]

14. Oyinbo CA (2011) Secondary injury mechanisms in traumatic spinal cord injury: a nugget of this multiply cascade. Acta Neurobiol Exp 71: 281-299. [PubMed]

15. Wisel S, Khan M, Kuppusamy ML, Mohan IK, Chacko SM, et al. (2009) Pharmacological preconditioning of mesenchymal stem cells with trimetazidine (1-[2,3,4-trimethoxybenzyl]piperazine) protects hypoxic cells against oxidative stress and enhances recovery of myocardial function in infarcted heart through Bcl-2 expression. J Pharmaco Exp Ther 329: 543-550. [PubMed]

16. Huang W, Wang T, Zhang D, Zhao T, Dai B, et al. (2012) Mesenchymal stem cells overexpressing CXCR4 attenuate remodeling of postmyocardial infarction by releasing matrix metalloproteinase-9. Stem Cells Dev 21: 778-789. [PubMed]

17. Hu X, Yu SP, Fraser JL, Lu Z, Ogle ME, et al. (2008) Transplantation of hypoxiapreconditioned mesenchymal stem cells improves infarcted heart function via enhanced survival of implanted cells and angiogenesis. J Thorac Cardiovasc Surg 135: 799-808. [PubMed]

18. Hu X, Wei L, Taylor TM, Wei J, Zhou X, et al. (2011) Hypoxic preconditioning enhances bone marrow mesenchymal stem cell migration via Kv2.1 channel and FAK activation. Am J Physiol Cell Physiol 301, C362-372. [PubMed]

19. Rosová I, Dao M, Capoccia B, Link D, Nolta JA (2008) Hypoxic preconditioning results in increased motility and improved therapeutic potential of human mesenchymal stem cells. Stem Cells 26: 2173-2182. [PubMed]

20. Lennon DP, Edmison JM, Caplan Al (2001) Cultivation of rat marrow-derived mesenchymal stem cells in reduced oxygen tension: effects on in vitro and in vivo osteochondrogenesis. J Cell Physiol 187: 345-355. [PubMed]

21. Valorani MG, Montelatici E, Germani A, Biddle A, D'Alessandro D, et al. (2012) Pre-culturing human adipose tissue mesenchymal stem cells under hypoxia increases their adipogenic and osteogenic differentiation potentials. Cell Prolif 45: 225-238. [PubMed]

22. Neuss S, Becher E, Wöltje M, Tietze L, Jahnen-Dechent W (2004) Functional expression of HGF and HGF receptor/c-met in adult human mesenchymal stem cells suggests a role in cell mobilization, tissue repair, and wound healing. Stem Cells 22: 405-414. [PubMed]

23. Jin K, Zhu Y, Sun Y, Mao XO, Xie L, et al. (2002) Vascular endothelial factor (VEGF) stimulates neurogenesis in vitro and in vivo. Proc Natl Acad Sci USA 99: 11946-11950. [PubMed]

24. Storkebaum E, Lambrechts D, Carmeliet P (2004) VEGF: once regarded as a specific angiogenic factor, now implicated neuroprotection. Bioessays 26: $943-$ 954. [PubMed]

25. Chacko SM, Ahmed S, Selvendiran K, Kuppusamy ML, Khan M, et al. (2010) Hyopxic preconditioning induces the expression of prosurvival and proangiogenic markers in mesenchymal stem cells. Am J Cell Physiol 299: C1562-1570. [PubMed]

26. Chang CP, Chio CC, Cheong CU, Chao CM, Cheng BC, et al. (2013) Hypoxic preconditioning enhances the therapeutic potential of the secretome from cultured human mesenchymal stem cells in experimental traumatic brain injury. Clin Sci 124: 165-176. [PubMed]

27. Liu L, Gao J, Yuan Y, Chang Q, Liao Y, et al. (2013) Hypoxia preconditioned human adipose derived mesenchymal stem cells enhances angiogenic potential via secretion of increased VEGF and bFGF. Cell Biol Int 37: 551-560. [PubMed]

28. Tai MH, Cheng H, Wu JP, Liu YL, Lin PR, et al. (2003) Gene transfer of glial cell line-derived neurotrophic factor promotes functional recovery following spinal cord contusion. Exp Neurol 183: 508-515. [PubMed]

29. Wells JE, Rice TK, Nuttall RK, Edwards DR, Zekki H, et al. (2003) An adverse role for matrix metalloproteinase 12 after spinal cord injury in mice. J Neurosc 23: 10107-10115. [PubMed]

30. Basso DM, Beattie MS, Bresnahan JC (1995) A sensitive and reliable locomotor rating scale for open field testing in rats. J Neurotrauma 12: 1-21. [PubMed]

31. Pomiès $P$, Blaquière $M$, Maury $J$, Mercier $J$, Gouzi $F$, et al. (2015) Involvement of the FoxO1/MuRF1/Atrogin-1 Signaling Pathway in the Oxidative StressInduced Atrophy of Cultured Chronic Obstructive Pulmonary Disease Myotubes. PLoS One 11: e0160092. [PubMed]
32. Rademakers SE, Lok J, van der Kogel AJ, Bussink J, Kaanders JH (2011) Metabolic markers in relation to hypoxia; staining patterns and colocalization of pimonidazole, HIF-1a, CA, LDH-5, GLUT-1, MCT1 and MCT4. BMC Cancer 11: 167. [PubMed]

33. Potier E, Ferreira E, Meunier A, Sedel L, Logeart-Avramoglou D, et al. (2007) Prolonged hypoxia concomitant with serum deprivation induces massive human mesenchymal stem cell death. Tissue Eng 13: 1325-1331. [PubMed]

34. Imura T, Matsumoto M, Fukazawa T, Khalesi E, Sun SY, et al. (2013) Interactive effects of cell therapy and rehabilitation realize the full potential of neurogenesis in brain injury model. Neurosci Lett 555: 73-78. [PubMed]

35. Li T, Jiang L, Zhang X, Chen H (2009) In-vitro effects of brain-derived neurotrophic factor on neural progenitor-stem cells from rat hippocampus. Neuroreport 20: 295-300. [PubMed]

36. Tajiri N, Yasuhara T, Shingo T, Kondo A, Yuan W, et al. (2010) Exercise exerts neuroprotective effects on Parkinson's disease model of rats. Brain Res 1310: 200-207. [PubMed]

37. Nakamura K, Martin KC, Jackson JK, Beppu K, Woo CW, et al. (2006) Brain -derived neurotrophic factor activation of TrkB induces vascular endothelia growth factor expression via hypoxia-inducible factor-1 alpha in neuroblastoma cells. Cancer Res 66: 4249-4255. [PubMed]

38. Sun CY, Hu Y, Huang J, Chu ZB, Zhang L, et al. (2010) Brain-derived neurotrophic factor induces proliferation, migration, and VEGF secretion in human multiple myeloma cells via activation of MEK-ERK and PI3K/AKT signaling. Tumour Biol 31: 121-128. [PubMed]

39. Deindl E (2014) Mechanistic insights into the functional role of vascular endothelial growth factor and its signalling partner brain derived neurotrophic factor in angiogenic tube formation. Acta Physiol 211: 268-270. [PubMed]

40. Usui T, Naruo A, Okada M, Hayabe Y, Yamasaki H (2014) Brain-derived neurotrophic factor promotes angiogenic tube formation through generation of oxidative stress in human vascular endothelial cells. Acta Physiol (Oxf) 211 385-394. [PubMed]

41. Chen J, Zhang C, Jiang H, Li Y, Zhang L, et al. (2005) Atorvastatin induction of VEGF and BDNF promotes brain plasticity after stroke in mice. J Cereb Blood Flow Metab 25: 281-290. [PubMed]

42. Du Y, Ji X (2014) Bcl-2 down-regulation by small interfering RNA induces Beclin 1-dependent autophagy in human SGC-7901 cells. Cell Biol Int 38: 1155-1162.

43. Chen A, Xiong LJ, Tong Y, Mao M (2013) Neuroprotective effect of brainderived neurotrophic factor mediated by autophagy through the PI3K/Akt/ mTOR pathway. Mol Med Rep 8: 1011-1016. [PubMed]

44. Wang H, Wang Y, Li D, Liu Z, Zhao Z, et al. (2015) VEGF inhibits the inflammation in spinal cord injury through activation of autophagy. Biochem Biophys Res Commun 464: 453-458. [PubMed]

45. Chen H, Yan Y, Davidson TL, Shinkai Y, Costa M (2006) Hypoxic stress induces demethylated histone $\mathrm{H} 3$ lysine 9 through histone methyltransferase G9a in mammalian cells. Cancer Res 66: 9009-9016. [PubMed]

46. Ueda J, Ho JC, Lee KL, Kitajima S, Yang H, et al. (2014) The hypoxia-inducible epigenetic regulators Jmjd1a and G9a provide a mechanistic link between angiogenesis and tumor growth. Mol Cell Biol 34: 3702-3720. [PubMed]

47. Zhang T, Termanis A, Özkan B, Bao XX, Culley J, et al. (2016) G9a/GLP complex maintains imprinted DNA methylation in embryonic stem cells. Cell Rep 15: 77-85. [PubMed]

48. Cassidy SB, Dykens E, Williams (2000) Prader-Willi and Angelman syndromes: sister imprinted disorders. Am J Med Genet 97: 136-146. [PubMed]

49. Hausmann ON (2003) Post-traumatic inflammation following spinal cord injury. Spinal Cord 41: 369-378. [PubMed]

50. Yu F, Kamada H, Niizuma K, Endo $\mathrm{H}$, Chan $\mathrm{PH}$ (2008) Induction of mmp- 9 experssion and endothelial injury by oxidative stress after spinal cord injury. $J$ Neurotrauma 25: 184-195. [PubMed]

51. Sekine Y, Hatanaka R, Watanabe T, Sono N, lemura S (2012) The Kelch repeat protein KLHDC10 regulates oxidative stress-induced ASK1 activation by suppressing PP5. Mol Cell 48: 692-704. [PubMed]

52. Nako H, Kataoka K, Koibuchi N, Dong YF, Toyama K, et al. (2012) Nove mechanism of angiotensin II-induced cardiac injury in hypertensive rats: the critical role of ASK1 and VEGF. Hypertens Res 35: 194-200. [PubMed] 
Citation: Imura T, Tomiyasu M, Otsuru N, Nakagawa K, Otsuka T, et al. (2017) Hypoxic Preconditioning Increases the Neuroprotective Effects of Mesenchymal Stem Cells in a Rat Model of Spinal Cord Injury. J Stem Cell Res Ther 7: 375. doi: 10.4172/2157-7633.1000375

53. Leo M, Argalski S, Schäfers M, Hagenacker T (2015) Modulation of VoltageGated Sodium Channels by Activation of Tumor Nectosis Factor Receptor-1 and Receptor-2 in Small DRG Neurons of Rats. Mediators Inflamm 2015: 124942. [PubMed]

54. Murphy PG, Grondin J, Altares M, Richardson PM (1995) Induction of interleukin-6 in axotomized sensory neurons. J Neurosci 15: 5130-5138. [PubMed]
55. Schäfers M, Sorkin LS, Geis C, Shubayev VI (2003) Spinal nerve ligation induces transient upregulation of tumor necrosis factor receptors 1 and 2 in injured and adjacent uninjured dorsal root ganglia in the rat. Neurosci Lett 347 : 179-182. [PubMed]

56. Wang PP, Xie DY, Liang XJ, Peng L, Zhang GL, et al. (2012) HGF and direct mesenchymal stem cells contact synergize to inhibit hepatic stellate cells activation through TLR4/NF-kB pathway. PLoS One 7: e43408. [PubMed] 